\title{
Short- and long-term outcomes of pancreaticoduodenectomy in elderly patients with periampullary cancer
}

\author{
Jae Seung Kang ${ }^{1, *}$, Hongbeom Kim ${ }^{1, *}$, Jae Ri Kim¹, Youngmin Han¹, Eunjung Kim¹, Yoonhyeong Byun ${ }^{1}$, \\ Yoo Jin Choi ${ }^{1}$, Wooil Kwon', Jin-Young Jang ${ }^{1}$, Sun-Whe Kim² \\ ${ }^{1}$ Department of Surgery and Cancer Research Institute, Seoul National University College of Medicine, Seoul, Korea \\ ${ }^{2}$ Center for Liver and Pancreatobiliary Cancer, National Cancer Center, Goyang, Korea
}

\begin{abstract}
Purpose: Pancreaticoduodenectomy (PD) is recently performed in older cancer patients. The complication rate of PD is high. The present study was to compare the postoperative short- and long-term outcomes of PD in between older patients and younger patients.

Methods: Between 2000 and 2014, patients who underwent PD due to periampullary cancers were enrolled. Patients aged 75 years or over were included in the older group.

Results: Total 1,249 patients were enrolled in this study and 168 patients (13.5\%) were included in the older group. Postoperative complication rates, duration of postoperative hospital stay, and 30-day mortality were comparable between the 2 groups, although the admission rate of intensive care unit postoperatively was higher in the older adult group (20.8\% vs. $10.5 \%, \mathrm{P}<0.001)$. In terms of long-term outcomes, 5 -year overall survival rate was lower in the older group $(23.4 \%$ vs. $41.8 \%, P<0.001]$, and 5 -year cumulative recurrence rate was higher in the older group without statistical significance $163.9 \%$ vs. $57.9 \%, P=0.095)$. However, there were no statistical differences of cumulative recurrence in pancreatic cancer patients (81.5\% vs. $82.5 \%, P=0.805)$.

Conclusion: PD for periampullary cancer is a safe and feasible treatment in the older patients. The treatment modality for obtaining better survival outcomes will be investigated.

[Ann Surg Treat Res 2020;98(1):7-14]
\end{abstract}

Key Words: Geriatric assessment, Outcome assessment, Pancreaticoduodenectomy, Recurrence, Survival

\section{INTRODUCTION}

The number of older cancer patients increases worldwide [1]. Recently, age alone is not considered to be contraindicated to surgical treatment, and many studies revealed that the older patients should undergo the surgical treatment as same as the younger patients did [2-6].

Pancreaticoduodenectomy (PD) is highly invasive operation and complication rate is high. It considered to the treatment for the periampullary cancer. Some reports revealed that PD was safe and feasible for the older patients in the aspect of short-term outcomes [2,3,7-9]. However, there were some debates about whether PD had a survival benefit at long-term postoperative periods taking a high rate of postoperative complications. In addition, there were few reports about the safety and feasibility of PD in older patients with periampullary cancer in Korea. The present study was to investigate the perioperative short-term outcomes and long-term oncologic
Received July 26, 2019, Revised October 28, 2019,

Accepted November 15, 2019

\section{Corresponding Author: Sun-Whe Kim}

Center for Liver and Pancreatobiliary Cancer, National Cancer Center, 323

IIsan-ro, Ilsandong-gu, Goyang 10408, Korea

Tel: +82-31-920-1130, Fax: +82-31-920-1138

E-mail: sunkim@snu.ac.kr

ORCID: https://orcid.org/0000-0001-6315-6019
*Jae Seung Kang and Hongbeom Kim contributed equally to this study as co-first authors.

Copyright (c) 2020, the Korean Surgical Society

(c) Annals of Surgical Treatment and Research is an Open Access Journal. All articles are distributed under the terms of the Creative Commons Attribution NonCommercial License (http://creativecommons.org/licenses/by-nc/4.0/) which permits unrestricted non-commercial use, distribution, and reproduction in any medium, provided the original work is properly cited. 
outcomes comparing the elderly with other patients in Korean large-volume institution.

\section{METHODS}

\section{Patients and materials}

This study is a retrospective cohort study with prospectively collected medical data. Between January 2000 and December 2014, patients who underwent PD or pylorus-preserving PD (PPPD) were enrolled. All the patients had pathologic confirmation of periampullary cancer such as pancreatic, distal common bile duct (CBD), ampullary, and duodenal cancer, and each patient had only one type of periampullary cancer. Exclusion criteria were as follows: bile duct resection or enucleation, histologically benign disease, double-primary cancer, and combined other organ resection. However, PDs with combined vascular resection and anastomosis were not excluded.

Patients of 75 years or more than 75 years old were included in the older group, and those of less than 75 years old were included in the control group. Patient demographics and clinical outcomes were investigated. Postoperative complications were

Table 1. Patient demographics and perioperative outcomes according to the age groups

\begin{tabular}{|c|c|c|c|c|}
\hline Variable & $\begin{array}{c}\text { Total } \\
(\mathrm{n}=1,249)\end{array}$ & $\begin{array}{l}\text { Elderly group } \\
\qquad(\mathrm{n}=168)\end{array}$ & $\begin{array}{l}\text { Control group } \\
(\mathrm{n}=1,081)\end{array}$ & P-value \\
\hline Age (yr), median (IQR) & $64(57-71)$ & $77(76-79)$ & $62(56-68)$ & 0.001 \\
\hline Sex & & & & 0.202 \\
\hline Male & $765(61.2)$ & $95(56.5)$ & $670(62.0)$ & \\
\hline Female & $484(38.8)$ & $73(43.5)$ & $411(38.0)$ & \\
\hline Body mass index $\left(\mathrm{kg} / \mathrm{m}^{2}\right)$ & $23.0 \pm 3.1$ & $22.6 \pm 3.1$ & $23.0 \pm 3.1$ & 0.144 \\
\hline Preoperative comorbidity & $677(54.2)$ & $110(65.5)$ & $567(52.5)$ & 0.002 \\
\hline ASA PS classification & & & & 0.001 \\
\hline I and II & $1,173(93.9)$ & $147(87.5)$ & $1,026(94.9)$ & \\
\hline III and IV & $76(6.1)$ & $21(12.5)$ & $55(5.1)$ & \\
\hline Surgery type & & & & 0.465 \\
\hline Whipple's operation & $358(28.7)$ & $44(26.2)$ & $314(29.0)$ & \\
\hline PPPD & $891(71.3)$ & $124(73.8)$ & $767(71.0)$ & \\
\hline R0 resection & 1,088 (88.6) & $147(87.5)$ & $959(88.7)$ & 0.696 \\
\hline Operation time (min) & $335.1 \pm 85.1$ & $323.2 \pm 76.6$ & $337.4 \pm 86.0$ & 0.042 \\
\hline Estimated blood loss (mL) & $450.8 \pm 494.4$ & $415.0 \pm 338.2$ & $458.96 \pm 517.6$ & 0.337 \\
\hline Postoperative ICU stay & $148(11.8)$ & $35(20.8)$ & $113(10.5)$ & $<0.001$ \\
\hline Diagnosis & & & & 0.368 \\
\hline Pancreatic cancer & $451(36.1)$ & $56(32.3)$ & $395(36.5)$ & \\
\hline Common bile duct cancer & $383(30.7)$ & $59(35.1)$ & $324(30.0)$ & \\
\hline Ampulla of Vater cancer & $365(29.2)$ & $44(26.2)$ & $321(29.7)$ & \\
\hline Duodenal cancer & $50(4.0)$ & $9(5.4)$ & $41(3.8)$ & \\
\hline AJCC 7th staging & & & & 0.868 \\
\hline 0 & $31(2.5)$ & $3(1.8)$ & $28(2.6)$ & \\
\hline I & $293(23.5)$ & $38(22.6)$ & $255(23.6)$ & \\
\hline II & $849(68.0)$ & $115(68.5)$ & $734(67.9)$ & \\
\hline III & $51(4.1)$ & $9(5.4)$ & $42(3.9)$ & \\
\hline IV & $25(2.0)$ & $3(1.8)$ & $22(2.0)$ & \\
\hline Overall complications & $720(57.6)$ & $100(59.5)$ & $620(57.4)$ & 0.615 \\
\hline Postoperative pancreatic fistula & $394(31.5)$ & $68(40.5)$ & $326(30.2)$ & 0.008 \\
\hline Pancreatic cancer & $73(16.2)$ & $9(16.1)$ & $64(16.2)$ & 0.999 \\
\hline Distal common bile duct cancer & $175(45.7)$ & $40(67.8)$ & $135(41.7)$ & 0.001 \\
\hline Ampulla of Vater cancer & $127(34.8)$ & $15(34.1)$ & $112(34.9)$ & 0.999 \\
\hline Duodenal cancer & $19(38.0)$ & $4(44.4)$ & $15(36.6)$ & 0.715 \\
\hline Postoperative hospital stay (day) & $20.4 \pm 11.2$ & $20.5 \pm 11.8$ & $20.5 \pm 11.2$ & 0.922 \\
\hline Postoperative 30-day mortality & $4(0.3)$ & $1(0.6)$ & $3(0.3)$ & 0.999 \\
\hline Adjuvant chemotherapy & $764(61.2)$ & $48(28.6)$ & $716(66.2)$ & $<0.001$ \\
\hline Overall recurrences & $676(54.1)$ & $86(51.2)$ & $590(54.6)$ & 0.454 \\
\hline
\end{tabular}

Values are presented as number $(\%)$ or mean \pm standard deviation unless otherwise indicated.

IQR, interquartile range; ASA PS, American Society of Anesthesiologists physical status; ICU, intensive care unit; PPPD, pyloruspreserving pancreatoduodenectomy; AJCC, American Joint Committee on Cancer. 
evaluated if their Clavian-Dindo classification were grade II or above [10]. A postoperative regular surveillance was performed with chest, abdominal pancreatobiliary protocol computed tomography and cancer markers (serum CEA and CA 199) at every 3 months for 2 years and at every 4 to 6 months after postoperative 2 years. If recurrence was noted, the patients additionally underwent PET-CT and MRI, and a tissue biopsy if needed. Overall survival (OS) rates and cumulative recurrence $(\mathrm{CR})$ rate also analyzed. This study was approved by the Institutional Review Board in Seoul National University Hospital (C-1606-028-768).

\section{Statistical analysis}

Factors in the older and control groups were compared using Student t-tests for continuous variables and $\chi^{2}$ tests for categorical variables. The Kaplan-Meier method was used to estimate OS and CR rates. Variables for which $\mathrm{P}<0.05$ in univariate analysis were entered into a multivariate Cox-proportional hazards regression model to determine risk factors independently associated with adverse outcomes. Odds ratios and $95 \%$ confidence intervals (CIs) were calculated. All statistical analyses used IBM SPSS Statistics ver. 22.0 (IBM Co., Armonk, NY, USA) and R ver. 3.2.5 (R Foundation, Vienna, Austria).

\section{RESULTS}

\section{Demographics and perioperative outcomes}

Total 1,249 patients were enrolled in this study. Table 1 shows overall patient characteristics and perioperative outcomes. Median age of total patients was 64 years; 765 patients (61.2\%) were male; 76 patients (6.1\%) had American Society of Anesthesiologists (ASA) physical status classification of III or IV; 148 patients (11.8\%) were admitted to intensive care unit (ICU) after the surgery; 1,088 patients (88.6\%) obtained R0 resection status; The majority of diagnosis was pancreatic cancer (36.1\%), followed by CBD cancer (30.7\%); overall complication rate was 57.6\%; Overall postoperative pancreatic fistula (POPF) occurred in 394 patients (31.5\%); Four patients (0.3\%) died within postoperative 30 days; 764 patients $(61.2 \%)$ underwent adjuvant chemotherapy and overall recurrence rate was $54.1 \%$

\section{Comparisons of clinical findings and short-term outcomes between the 2 groups}

The number of older group, more than 75 years, was 168 (13.5\%). Median age of older group was 77 years and that of control group was 62 . Of the entire patients, the proportion of older group who were diagnosed of periampullary cancer (Fig. 1A) and those who received adjuvant chemotherapy (Fig. 1B) increased over time. The older group had higher ASA physical status classification of III or IV (12.5 vs. 6.1\%, P = 0.001), more preoperative comorbidity $(65.5 \%$ vs. $52.5 \%, \mathrm{P}=0.002)$, and less performing adjuvant treatment (28.6\% vs. $66.2 \%, \mathrm{P}<0.001)$. POPF occurred more in the older group than in the control group ( $40.5 \%$ vs. $30.2 \%, P=0.008$ ). However, after stratification with diagnoses, POPF occurred comparably in each diagnosis, such as pancreatic cancer (16.2 vs. $16.1 \%, P=0.999)$, ampullary cancer (34.9\% vs. 34.1\%, $\mathrm{P}=0.999)$, and duodenal cancer (44.4\% vs. $36.6 \%, P=0.715)$, except for distal CBD cancer $(67.8 \%$ vs. $41.7 \%, P=0.001)$. R0 resection rate was comparable between the 2 groups ( $88.7 \%$ vs. $87.5 \%, P=0.696)$. The distribution of cancer types and American Joint Committee on Cancer 7th staging was comparable between the 2 groups.

In terms of short-term outcomes, the duration of postoperative hospital stay (20.5 days vs. 20.5 days, $\mathrm{P}=0.922$ ), postoperative complication rates $(59.5 \%$ vs. $57.4 \%, \mathrm{P}=0.615)$, and in-hospital mortality (0.6\% vs. $0.3 \%, \mathrm{P}=0.999)$ were comparable between the 2 groups, although the admission rate of ICU postoperatively was higher in the elderly than the control group $(20.8 \%$ vs. $10.5 \%, \mathrm{P}<0.001)$.

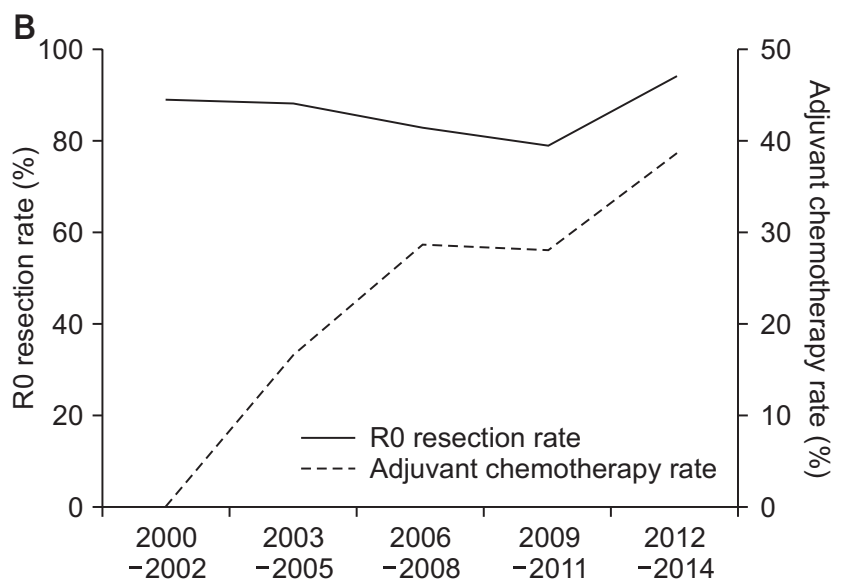

Fig. 1. (A) Proportion of the elderly patients in pancraticoduodenectomy for periampullary cancer. (B) The rates of R0 resection status and receiving chemotherapy in the elderly group. 


\section{Comparisons of OS and CR rate between the}

\section{2 groups}

In regards to the patients who obtained R0 resection status,

5-year OS rate was also worse $(25.2 \%$ vs. $43.7 \%, \mathrm{P}<0.001)$ (Fig.
2A). In subgroup analysis of each periampullary cancer among R0 patients, 5-year OS rates were lower in all disease types between the 2 groups that significant difference was shown in distal CBD (23.4\% vs. 51.5\%, $\mathrm{P}=0.001)$ and ampullary cancer
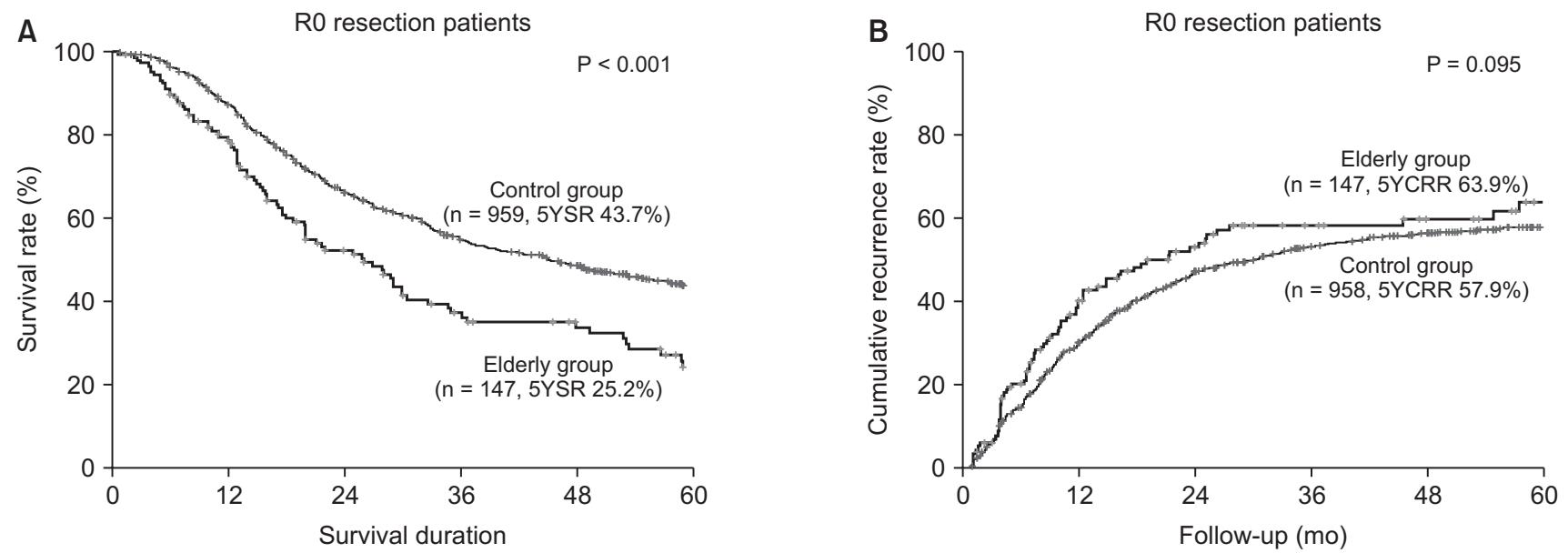

Fig. 2. Comparisons of survival outcomes between the older and control groups who obtained R0 resection status. (A) The 5-year overall survival rate, (B) 5-year cumulative recurrence rate. 5YSR, 5-year overall survival rate; 5YCRR, 5-year cumulative recurrence rate.
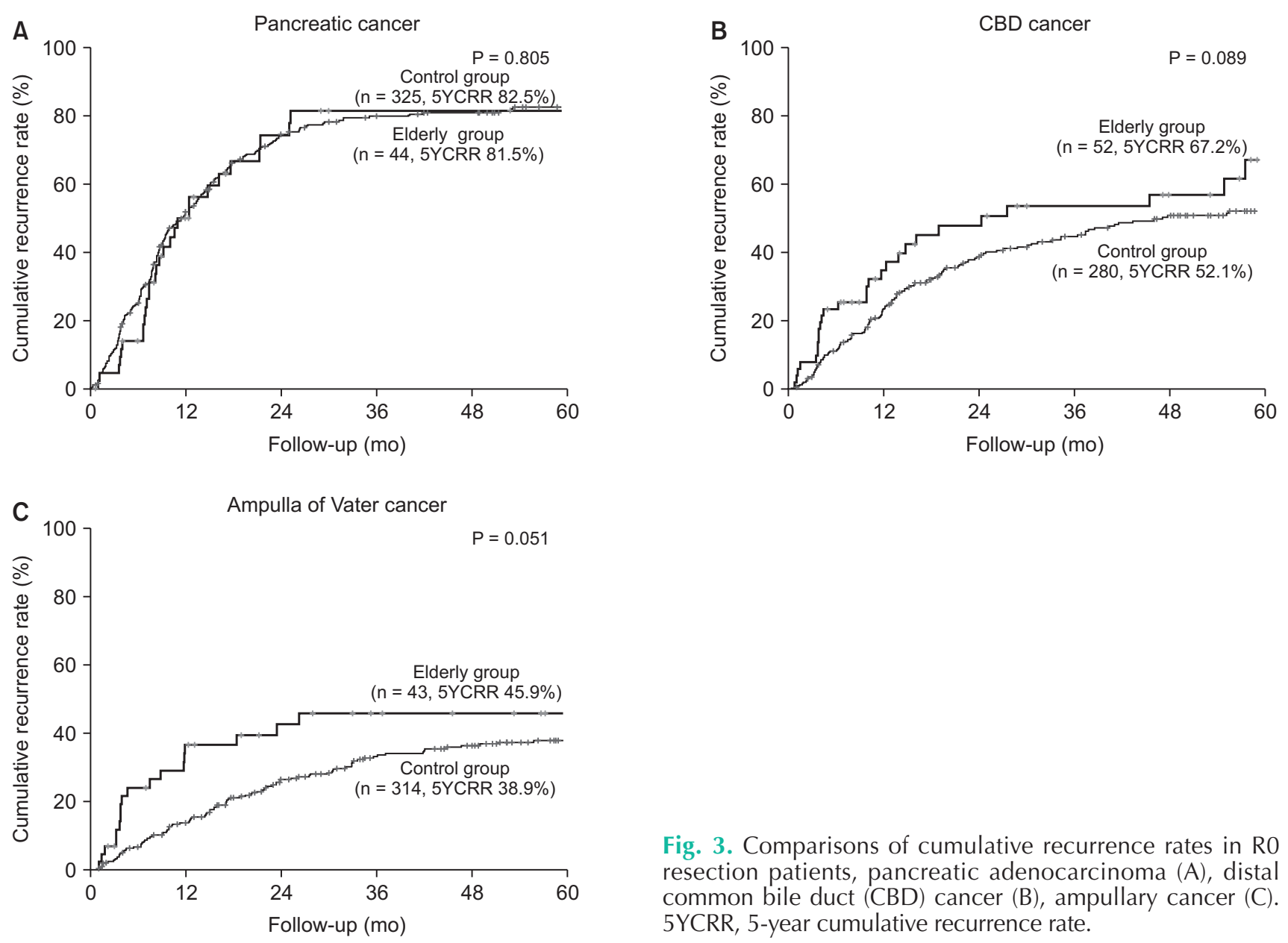

Fig. 3. Comparisons of cumulative recurrence rates in R0 resection patients, pancreatic adenocarcinoma (A), distal common bile duct (CBD) cancer (B), ampullary cancer (C). 5YCRR, 5-year cumulative recurrence rate. 
(47.8\% vs. $60.4 \%, \mathrm{P}=0.009$ ), but no significant difference in pancreas $(7.0 \%$ vs. $19.6 \%, P=0.078)$ and duodenum cancer ( $28.6 \%$ vs. $46.9 \%, P=0.393$ ). Five-year $\mathrm{CR}$ rate in the older group was also worse than in the control group without statistical significance (63.9\% vs. $57.2 \%, \mathrm{P}=0.095)$ (Fig. 2B). In subgroup analysis, no statistical differences of $\mathrm{CR}$ rate were shown in pancreatic cancer (81.5\% vs. $82.5 \%, \mathrm{P}=0.805$ ) (Fig. 3A), distal CBD cancer (67.2\% vs. 52.1\%, $\mathrm{P}=0.089$ ) (Fig. 3B), and ampullary cancer (45.9\% vs. 38.1\%, $\mathrm{P}=0.051$ ) (Fig. 3C) between the older and control groups.

\section{Prognostic factors associated with survival outcomes in the older group}

Univariate analysis showed that the presence of preoperative comorbidity, postoperative ICU stay, PD operation, and lymph node metastasis were associated with adverse survival outcomes in the older group (Table 2). In a multivariate Coxproportional hazard model, the presence of comorbidity (hazard ratio $[\mathrm{HR}], 2.008 ; 95 \% \mathrm{CI} 1.300-3.103 ; \mathrm{P}=0.002)$, lymph node metastasis (HR, 2.957; 95\% CI, 1.910-4.579; $\mathrm{P}=0.001$ ), and pathologic diagnoses were the independent risk factors associate with poor survival outcome in the older group.

\section{DISCUSSION}

Despite the development of surgical skills and perioperative management, the postoperative morbidity rate after PD remained high, ranged $40 \%$ to $50 \%[11,12]$. The older patients who had periampullary cancer increased worldwide, and the safety, feasibility and survival outcomes for the older patients who underwent curative-intent PD become interested to the surgeons. In the present study, the proportion of patients who underwent PD was increased over time, and it was approximately 20\% in 2013-2014 (Fig. 1A). Most studies insisted that the postoperative morbidity rate was comparable between the older and control groups, but the 5-year survival rate was controversial $[3,8,9,11,12]$. Table 3 summarizes these results.

The study performed by Makary et al. [11] was the largest one that enrolled 2,698 PD patients in Johns Hopkins Hospital. It contained over 1,000 patients with pancreatic cancer, and

Table 2. Prognostic factors in univariate and multivariate analysis in the elderly group

\begin{tabular}{|c|c|c|c|c|c|c|}
\hline \multirow{2}{*}{ Variable (reference) } & \multicolumn{3}{|c|}{ Univariate analysis } & \multicolumn{3}{|c|}{ Multivariate analysis } \\
\hline & Patients & $5-Y S R(\%)$ & P-value & $H R$ & $95 \% \mathrm{Cl}$ & P-value \\
\hline Male sex (female) & $73 / 95$ & $22.8 / 17.4$ & 0.214 & & & \\
\hline ASA PS classification (I and II), III and IV & $147 / 21$ & $22.0 / 19.0$ & 0.244 & & & \\
\hline Preoperative comorbidity (no), yes & $58 / 110$ & $34.9 / 15.0$ & 0.008 & 2.008 & $1.300-3.103$ & 0.002 \\
\hline Postoperative ICU stay (no), yes & $35 / 133$ & $24.4 / 0.0$ & 0.045 & 1.576 & $0.904-2.749$ & 0.109 \\
\hline Operation type (PPPD), PD & $124 / 44$ & $25.3 / 14.1$ & 0.042 & 1.309 & $0.838-2.045$ & 0.237 \\
\hline Resection status (R0), R1 & $147 / 21$ & $24.2 / 15.2$ & 0.135 & & & \\
\hline $\mathrm{N}$ stage $(\mathrm{N} 0), \mathrm{N}+$ & $102 / 66$ & $34.2 / 4.1$ & 0.001 & 2.957 & $1.910-4.579$ & 0.001 \\
\hline Adjuvant treatment (no), yes & $120 / 48$ & $26.1 / 12.1$ & 0.064 & & & \\
\hline Pathologic diagnosis & & & 0.001 & & & \\
\hline Ampullary cancer & 44 & 45.0 & & & & \\
\hline Common bile duct cancer & 59 & 22.8 & & 1.825 & $1.038-3.210$ & 0.037 \\
\hline Pancreatic cancer & 56 & 7.0 & & 2.924 & $1.705-5.014$ & 0.001 \\
\hline
\end{tabular}

5-YSR, 5-year survival rate; HR, hazard ratio; Cl, confidence interval; ASA PS, American Society of Anesthesiologists physical status; ICU, intensive care unit; PPPD, pylorus-preserving pancreatoduodenectomy; PD, pancreatoduodenectomy.

Table 3. Previous studies comparing the morbidity and survival outcomes between the older and younger group

\begin{tabular}{lcclll}
\hline \multicolumn{1}{c}{ Study } & $\begin{array}{c}\text { Cutoff } \\
\text { age }(\mathrm{yr})\end{array}$ & Older group, $\mathrm{n}(\%)$ & Disease & In-hospital morbidity & 5-Year survival rate \\
\hline Kim et al. [8] & 80 & $17(10.3)$ & PDAC & Comparable & Lower in the old group \\
Lee et al. [12] & 80 & $45(11.5)$ & PDAC & Comparable & Lower in the old group \\
Makary et al. [11] & 80 & $207(7.7)$ & All & Comparable & Lower in the old group \\
Casadei et al. [9] & 80 & $32(14.3)$ & All & Comparable & Comparable \\
Kang et al. [3] & 70 & $11(14.3)$ & PDAC & Higher in the old group & Comparable \\
Present study & 75 & $168(13.5)$ & All & Comparable & Lower in the old group \\
\hline
\end{tabular}

PDAC, pancreatic ductal adenocarcinoma; All, all periampullary cancer. 
the cutoff ages were 80 and 90 years. However, the enrolled period was from 1970 to 2005 , it contained both benign and malignant periampullary diseases, and the number of surgeons participated in the study was 24 . The present study was one of the largest, retrospective cohort studies with the prospectively collected medical data. The enrolled period was relatively recent, ranged 2000 to 2014, and only 3 surgeons participated with similar operation procedure - the heterogeneity of extent of surgery was minimized. In addition, this study provided the survival rates not only in pancreatic cancer, but also other periampullary cancer such as distal $\mathrm{CBD}$, ampullary, and duodenal cancer.

In this study, we defined the older group as the patients more than 75 years old. One of the reasons was that the number of patients aged more than 80 years old was too small to derive statistical significance $(n=39,3.1 \%)$. Furthermore, we had performed the statistical analysis based on the age criteria of not only 75 but also 70 and 80 years, and the results were similar that the short-term complication rate and the recurrence rate were not significantly different between the older and control groups based on each age criterion.

Among 4 mortality cases, only one was due to surgical complication, hepaticojejunostomy leakage leading to sepsis and the patient was in the control group. Other patients died because of medical problems such as pneumonia (1 in the older group, 1 in the control group) and cardiogenic problem (control group). In the present study, the duration of postoperative hospital stay (20.5 days vs. 20.5 days, $P=0.922$ ), the proportion of R0 resection status was comparable between the 2 groups (87.5\% vs. $88.7 \%, P=0.696)$, and overall complication rates were also comparable (59.5 vs. $57.4 \%, \mathrm{P}=0.615$ ). Generally, POPF occurred more in the older group in this study. However, the incidence of POPF was comparably between the 2 groups according to the diagnoses, except for distal CBD cancer. In terms of short-term outcome, age alone might not be contraindicated with PD and surgeons have to perform the adequate surgeries in order to obtain $\mathrm{R} 0$ resection status which was one of the prognostic factors related with better outcome [13-18].

One study proposed that the prognosis of old patients with pancreatic cancer was worse than that of young patients, probably because of less completion of adjuvant chemotherapy [19]. The older patients tended to undergo adjuvant chemotherapy less frequently for many reasons, probably such as patients' denial, toxicity of chemotherapy agents, and postoperatively unrecovered patients' performance status $[20,21]$. In the present study, the patients who underwent adjuvant chemotherapy were significantly less in the older than the control group (28.6\% vs. $66.2 \%, \mathrm{P}<0.001)$ (Table 1 ). Although five-year OS rate was lower in the older group (23.4\% vs. $41.8 \%, \mathrm{P}<0.001$ ), it would occurr because of not only low rates of patients who received chemotherapy, but also less life expectancy of older patients.

In regards to the R0 resection patients, 5-year OS rate in the older group was lower than that in the control group (25.2\% vs. 43.7\%, P < 0.001) (Fig. 2A). In subgroup analysis of the diagnoses, 5-year OS rates were lower in all disease types between the 2 groups that significant difference was shown in distal CBD (23.4\% vs. $51.5 \%, \mathrm{P}=0.001)$ and ampullary cancer ( $47.8 \%$ vs. $60.4 \%, P=0.009$ ), but no significant difference in pancreas $(7.0 \%$ vs. $19.6 \%, P=0.078)$. Because pancreatic cancer is so aggressive, the 5-year OS rate of the control group and the older group might be indistinguishable. As the aggressiveness of distal CBD and ampullary cancers was less than that of pancreatic cancer, the power of cancer-related death might be smaller and 5-year OS rates of 2 diseases might be affected more by life expectancy.

In subgroup analysis of the older group, the present study showed in univariate analysis that patients who underwent postoperative chemotherapy had worse survival outcome than those who did not (5-year OS rate, $12.1 \%$ vs. $26.1 \%, \mathrm{P}=0.064$ ). However, in multivariate analysis, the chemotherapy was not the independent risk factor of worse survival outcomes in the older group. Five-year OS rates tended to be higher in chemotherapy-negative patients with no statistical significance than in chemotherapy-positive patients in terms of overall disease (26.1\% vs. $12.1 \%, P=0.064)$. And in subgroup analysis, no statistical differences of OS rate were shown in pancreatic adenocarcinoma ( $7.5 \%$ vs. $6.3 \%, \mathrm{P}=0.890$ ), and CBD cancer (22.0\% vs. $9.9 \%, P=0.088)$. One study reported that response rate of chemotherapy in older patients was similar to that in younger patients [22], and another study reported that chemotherapy would decrease mortality in older patients [23]. In the present study, the rate of patients in the older group who received chemotherapy was increasing, recently up to $40 \%$ (Fig. 1B). Further research would be needed for evaluating the effect of adjuvant chemotherapy on older patients and establishing the evidence-based indications of selecting appropriate candidates for it.

The present study has some limitations. First, this study was a retrospective cohort study. Especially, in case of patients who did not have the exact mortality data based on medical record, the time of death was estimated by data of Korea National Statistical Office or National Health Insurance Service database. However, National Health Insurance Service database does not include exact cause of death. Therefore, the exact diseasespecific survival rate could not be investigated. Second, there were some missing data in regards to the chemotherapy that some patients did not undergo adjuvant treatment in our hospital, mainly because the patients wanted to move the hospital for the adjuvant treatment near their hometown. Third, the present study failed to prove chemotherapy effect on survival benefit of the older patients. However, stage I patients existed 
more frequently in chemo-negative group than in chemopositive group ( $31.3 \%$ vs. $4.2 \%$ ). In addition, many older patients did not receive adjuvant chemotherapy, and they received it by various regimens because of performance status of patients, drug toxicity, and long study period.

In conclusion, PD for periampullary cancer is a safe and feasible treatment in the older patients, and surgeons should perform the same procedures and endeavor to obtain the same goal as the younger patients do. The methods for obtaining better survival outcomes including adjuvant chemotherapy will be investigated.

\section{CONFLICTS OF INTEREST}

No potential conflict of interest relevant to this article was reported.

\section{ACKNOWLEDGEMENTS}

This research was supported by a grant of the Korea Health Technology R\&D Project through the Korea Health Industry Development Institute KHIDI, funded by the Ministry of Health \& Welfare, Republic of Korea (grant number: HI14C2640) and the Collaborative Genome Program for Fostering New PostGenome Industry of the National Research Foundation funded by the Ministry of Science and ICT (NRF-2017M3C9A5031591).

\section{REFERENCES}

1. Eshuis WJ, van Eijck CH, Gerhards MF, Coene PP, de Hingh IH, Karsten TM, et al. Antecolic versus retrocolic route of the gastroenteric anastomosis after pancreatoduodenectomy: a randomized controlled trial. Ann Surg 2014:259:45-51.

2. Casadei R, Zanini N, Morselli-Labate AM, Calculli L, Pezzilli R, Poti O, et al. Prognostic factors in periampullary and pancreatic tumor resection in elderly patients. World J Surg 2006;30:1992-2001.

3. Kang CM, Kim JY, Choi GH, Kim KS, Choi JS, Lee WJ, et al. Pancreaticoduodenectomy of pancreatic ductal adenocarcinoma in the elderly. Yonsei Med J 2007;48:48894.

4. Katai H, Sasako M, Sano T, Maruyama $\mathrm{K}$. The outcome of surgical treatment for gastric carcinoma in the elderly. Jpn J Clin Oncol 1998:28:112-5.

5. Kim DY, Joo JK, Ryu SY, Park YK, Kim YJ, Kim SK. Clinicopathologic characteristics of gastric carcinoma in elderly patients: a comparison with young patients. World J Gastroenterol 2005;11:22-6.

6. Lee CR, Lim JH, Kim SH, Ahn SH, Park YN, Choi GH, et al. A comparative analysis of hepatocellular carcinoma after hepatic resection in young versus elderly patients. J Gastrointest Surg 2012;16:1736-43.

7. Gerstenhaber F, Grossman J, Lubezky
N, Itzkowitz E, Nachmany I, Sever R, et al. Pancreaticoduodenectomy in elderly adults: is it justified in terms of mortality, long-term morbidity, and quality of life? J Am Geriatr Soc 2013;61:1351-7.

8. Kim SY, Fink MA, Perini M, Houli N, Weinberg L, Muralidharan V, et al. Age 80 years and over is not associated with increased morbidity and mortality following pancreaticoduodenectomy. ANZ J Surg 2018;88:E445-50.

9. Casadei R, Taffurelli G, Silvestri S, Ricci C, Campra D, Minni F. Is age a barrier to pancreaticoduodenectomy? An Italian dualinstitution study. Updates Surg 2015;67: 439-47.

10. Dindo D, Demartines N, Clavien PA. Classification of surgical complications: a new proposal with evaluation in a cohort of 6336 patients and results of a survey. Ann Surg 2004:240:205-13.

11. Makary MA, Winter JM, Cameron JL, Campbell KA, Chang D, Cunningham SC, et al. Pancreaticoduodenectomy in the very elderly. J Gastrointest Surg 2006;10: 347-56.

12. Lee MK, Dinorcia J, Reavey PL, Holden MM, Genkinger JM, Lee JA, et al. Pancreaticoduodenectomy can be performed safely in patients aged 80 years and older. J Gastrointest Surg 2010;14:1838-46.
13. Wagner M, Redaelli C, Lietz M, Seiler CA, Friess $\mathrm{H}$, Buchler MW. Curative resection is the single most important factor determining outcome in patients with pancreatic adenocarcinoma. Br J Surg 2004:91:58694.

14. Winter JM, Cameron JL, Campbell KA, Arnold MA, Chang DC, Coleman J, et al. 1423 pancreaticoduodenectomies for pancreatic cancer: a single-institution experience. J Gastrointest Surg 2006;10:1199-210.

15. DeOliveira ML, Cunningham SC, Cameron JL, Kamangar F, Winter JM, Lillemoe $\mathrm{KD}$, et al. Cholangiocarcinoma: thirty-oneyear experience with 564 patients at a single institution. Ann Surg 2007:245:75562.

16. Jang JY, Kim SW, Park DJ, Ahn YJ, Yoon YS, Choi MG, et al. Actual long-term outcome of extrahepatic bile duct cancer after surgical resection. Ann Surg 2005:241:7784.

17. Howe JR, Klimstra DS, Moccia RD, Conlon KC, Brennan MF. Factors predictive of survival in ampullary carcinoma. Ann Surg 1998:228:87-94.

18. Bakaeen FG, Murr MM, Sarr MG, Thompson GB, Farnell MB, Nagorney DM, et al. What prognostic factors are important in duodenal adenocarcinoma? Arch Surg 2000;135:635-41. 
19. Sho M, Murakami Y, Kawai M, Motoi F, Satoi S, Matsumoto I, et al. Prognosis after surgical treatment for pancreatic cancer in patients aged 80 years or older: a multicenter study. J Hepatobiliary Pancreat Sci 2016;23:188-97.

20. Aparicio T, Jouve JL, Teillet L, Gargot D, Subtil F, Le Brun-Ly V, et al. Geriatric factors predict chemotherapy feasibility: ancillary results of FFCD 2001-02 phase
III study in first-line chemotherapy for metastatic colorectal cancer in elderly patients. J Clin Oncol 2013:31:1464-70.

21. Kinoshita S, Sho M, Yanagimoto H, Satoi S, Akahori T, Nagai M, et al. Potential role of surgical resection for pancreatic cancer in the very elderly. Pancreatology 2015;15: 240-6.

22. Langer CJ, Manola J, Bernardo P, Kugler JW, Bonomi P, Cella D, et al. Cisplatin- based therapy for elderly patients with advanced non-small-cell lung cancer: implications of Eastern Cooperative Oncology Group 5592, a randomized trial. J Natl Cancer Inst 2002;94:173-81.

23. Giordano SH, Duan Z, Kuo YF, Hortobagyi GN, Goodwin JS. Use and outcomes of adjuvant chemotherapy in older women with breast cancer. J Clin Oncol 2006;24: 2750-6. 